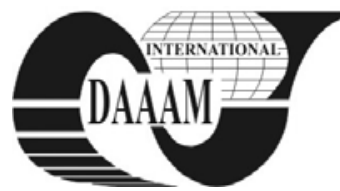

Annals of DAAAM for 2011 \& Proceedings of the 22nd International DAAAM Symposium, Volume 22, No. 1, ISSN 1726-9679 ISBN 978-3-901509-83-4, Editor B. Katalinic, Published by DAAAM International, Vienna, Austria, EU, 2011 Make Harmony between Technology and Nature, and Your Mind will Fly Free as a Bird Annals \& Proceedings of DAAAM International 2011

\title{
METHODOLOGY OF QUALIFICATION STANDARD DEVELOPMENT IN ICT BASED ON COMPETENCES MATRIX MODEL
}

\author{
BALKOVIC, M[islav] \& KRISTOF, T[omislav]
}

\begin{abstract}
In order to develop qualification standards based on learning outcomes concept, that is in line with EQF, new methodology of labor market research has been introduced. Respecting sectorial approach to qualification development and planning, Competences matrix was developed as efficient, straightforward, cheep and useful solution to group required competences gathered from differed sources, including employers. This approach reduces effort normally invested in development of Occupational standard by changing paradigm from detail description of work related activities and tasks to analysis of competences directly corresponding to learning outcomes in the qualification and curriculum.
\end{abstract}

Key words: competence, qualification, occupational standard, qualification framework, learning outcome

\section{INTRODUCTION}

Respecting recent global developments, most countries listed in upper part of global competitiveness list, already introduced or are currently working on development and implementation of national qualifications framework (NQF). Despite different approaches used, different state of affairs and level of achievement in different countries, all of them recognized NQF as a complex instrument that will link educational system and labor market hence fostering competitiveness of their national economy. In its core, NQF serves as a basis for accreditation of educational programs on any level and as a doorkeeper of educational achievement quality through number of registers populated with; occupations and its descriptions on one hand and knowledge, skills, learning outcomes and consequently qualifications and curriculums on the other. Each NQF in EU should be in line with European Qualifications Framework (EQF) wich has 8 levels of qualifications from primary school to $\mathrm{PhD}$, allowing qualifications from different countries and educational systems to be compared and mutually recognized.

Republic of Croatia started development of its NQF in May 2006 and till the end of 2010 there were no qualifications developed using proposed holistic approach that would be in line with EQF's concepts. Furthermore, there were no implementation guidelines for matching labor market requirements and qualifications development and until this work no methodology or model that is fully in line with the EQF's concepts was proposed.

\section{QUALIFICATION FRAMEWORK CONCEPTS}

Very heart of each NQF is matrix of Units of learning outcomes (Units) which serves as linking point of occupations on one hand and qualifications and curriculums on the other. In practice, one can depict Matrix of Units as two dimensional table with 8 levels on its vertical axis (representing EQF's levels) and number of columns on its horizontal axis representing different sectors or subsectors of applied skills and general knowledge. Respecting already mentioned sectorial approach, common to many EU countries, Croatia identified 13

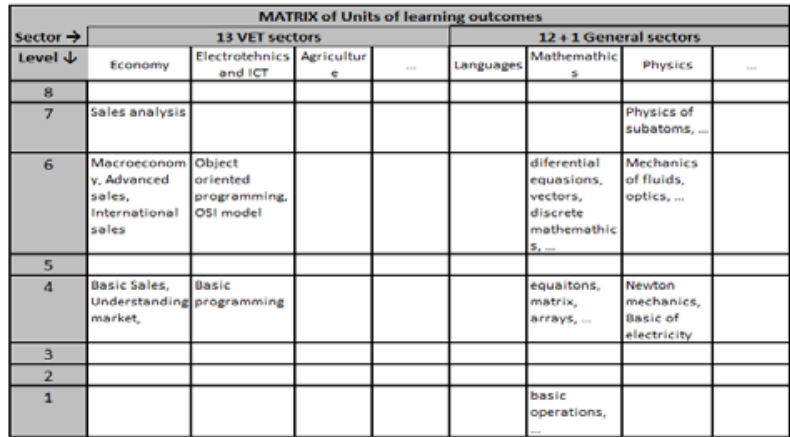

Tab. 1. Example of NQF - Matrix of Units of LO

specific applied skills sectors (also called VET sectors) and $12+1$ general sectors as shown in Tab. 1 .

Matrix of Units will typically host thousands of different units that are in practice small unique elements of competences (skills and knowledge) that will be a building blocks of all qualifications. Each Unit on higher level will be built respecting already existing units on lower level and each learning outcome that form unit (typically 5-10 of them) will correspond to referent level descriptor in order to match expected achievements with relevant level expectations. (Moon, 2004). Having all stated in mind one can conclude that the learning outcomes are important tools in clarifying the results of learning process for the students, citizens, employers and educators. On the other hand, we recognized competences as a single most important elements describing each occupation and/or work place and anchored our approach and methodology around similarity of competences and learning outcomes. The only difference between stated two terms is that learning outcome is reached after learning process and competence could be acquired anyhow - i.e. through work experience (Balkovic \& Korac, 2011).

\section{LABOR MARKET ANALYSIS}

In order to develop its NQF's, different approaches to determine required learning outcomes within qualifications were proposed and used. Basically there are very few countries in EU which managed to implement its NQF and therefore almost no applied methodologies were published or available. Still, countries that did significant work in the field, such as France, Netherlands and Malta, started from the development of Occupational standard, as we did, but using somewhat different approach. Firstly, they opted for in vivo surveying of employers while we used on-line as well as in vivo approach. Secondly, they missed to include other then employer driven competences early in the process and thirdly, they started from known "work tasks - activities" concept (as part of Occupational standard development), describing in detail work activities for different occupations linking them to required competences. In stated approaches significant expert work and effort is used to develop Occupational standard while on the other hand there is no documented systematic approach to transpose competences 
derived from the employers to Units of LO's building future Qualifications. Reference to this approach is available in published paper on recent Malta's achievements which is one of very few EU countries reported to have finished its NQF (Becker, 2009).

As in other already mentioned countries, labor market analysis was the key starting point to development of new qualification in our ICT project. Having in mind sectorial specifics, we opted for very simple and effective on-line survey questionnaire with only most important questions available to employers. They were asked to first enter up to 4 work places on which they have biggest number of employees in ICT sector on the secondary educational level, because we were tasked to develop one new secondary VET qualification. We asked them also to give short description (up to one sentence) of each work place in order for us to be able to latter group different work places and recognize corresponding occupations. Names of work places will greatly differ from one employer to another, but we intentionally opted for work places instead of occupations approach because employers know names of their work places and they do not necessarily have to know names of the occupations from ISCO08 list that we latter used. They were asked for work places on which they employ most employees because we estimated that at least for such a work places they really know which competences person must have to be competitive. In order also to take into consideration future trends, we asked employers also to identify additionally up to 2 work places on which they intend to employ in the future.

In the second part of the questionnaire, employers were asked to enter up to 9 specific applied and up to 9 general competences, person working on each work place they indicated should have. All stated competences gathered from the employers (more than 700 of them describing 130 different work places) were complemented with additional competences (more than 300 of them) from other sources such as; higher educational institutions (universities and colleges), national and EU development strategies (i.e. European e-Competence Framework 2.0), national framework curriculum and technological development outlooks $(* * *, 2008)$ and (***, 2009). Using stated approach we managed to identify and group all relevant competences from different sources assuring that the new qualifications will not only correspond to recent employers' requirements but also to future expected development in the professional field. Furthermore, having in mind necessity to increase number of highly educated persons in the workforce, we have taken also into account relevant requirements posed by higher educational institutions.

All gathered competences were first inserted in spreadsheet that we called Competences matrix and each of them was coded by; Type (vocational or professional), Level (NQF level) and Source (employer, strategy, higher edu...) as shown in Tab. 2.

In the second step names of work places given by employers, that were also included in the table, were linked to occupations and ISCO08 4 digit code of occupation was given to each of them (reducing 130 work places to 5 four digit groups of occupations). Finally, team of experts allocated each competence to corresponding group respecting their similarities. That way we got 11 general and 30 vocational groups (i.e. networking, security, mathematics...).

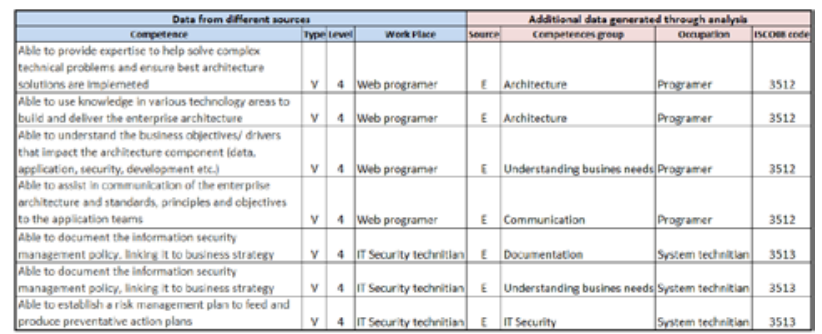

Tab. 2. Example of Competences matrix for ICT

\section{COMPETENCES MATRIX AS A TOOL IN CURRICULUM DEVELOPMENT}

Development of competences matrix allowed us to group competences gathered from different sources (not just employers) into logical groups, and to develop, as their match, Units of learning outcomes that closely correspond to them. During that work, each competence from the matrix was analyzed and those that were specific for just one employer or not corresponding to relevant NQF level were omitted, while learning outcomes were built to match others. Furthermore, with shown approach it was relatively easy not only to develop Units of learning outcomes but also to analyze which groups of competences are relevant for certain occupations, building that way Qualification standards that corresponds to one or more occupations, depending on similarities of occupations or, if you want, groups of Units they should consist of. Once finished and populated, Matrix of competences could be useful tool not only for Qualification standard development but also for development of curriculums because overlapping of groups of competences in similar occupations will yield curriculums with mandatory and elective modules to match Units in similar Qualifications. The most significant limitation of the proposed approach is quality of identified competences given by the employers, because they have never been educated to write them. Furthermore, since competences are not connected to work activities, it may sometimes be hard for them to think of the most important ones. This obstacle can be treated by increasing number of employers interviewed and more significant work done in the phase of preparation of LO's in qualification standards.

\section{CONCLUSION}

Proposed methodology, although used to develop only one qualification in one sub sector (ICT), proved itself as relatively simple and effective. In order to prepare Qualification standard, list of grouped competences was the most significant input information we needed, so we actually skipped the process of filling Occupational standard with the activities and, unlike others, asked for the competences instead. In order to pilot the methodology in other sectors further research is currently being done, while additional emphases should be put on fine tuning proposed methodology to match EURES's and ILO's employers surveys in order to get larger scale and constant information from the labor market, that this approach could provide if accepted by public employment service.

\section{REFERENCES}

Balkovic, M.; Korac, M. (2011). Methodology used for qualification standard and curriculum; "Technician for computing" development based on the learning outcomes concept and labor market analysis, Proceedings of the 34th International Convention, MIPRO 2011, Opatija, ISBN: 978-1-4577-0996-8, pp. 1039-1044

Becker, M. (2009) Competence matrix for the sector electronics / electrical engineering, VQTS-II project Leonardo da Vinci, Flensburg, Available from: http:// http://www.biat.uni-flensburg.de Accessed: 2011-10-02

Moon, J. (2004). Linking Levels, Learning Outcomes and Assesment Criteria, Exter University, Exter

*** (2008) http:// www.ictc-ctic.ca/default.aspx - Information and Communications Technology Council of Canada, "Outlook for Human Resources in the Information and Communications Technology Labour Market, 2008 to 2015", Accessed: 2011-10-02

*** (2009) http:// www.e-skills.com - The Sector Skills Council for Business and Information Technology - eskills, "Technology for Growth IT \& Telecoms Insights 2010”, Accessed: 2011-10-02 